\title{
Una reseña de Motricidad Orofacial II. Evaluación y diagnóstico
}

\author{
A review of Orofacial Myology II. Assessment and diagnosis \\ Irene Marchesan \\ Directora de CEFAC, Brasil
}

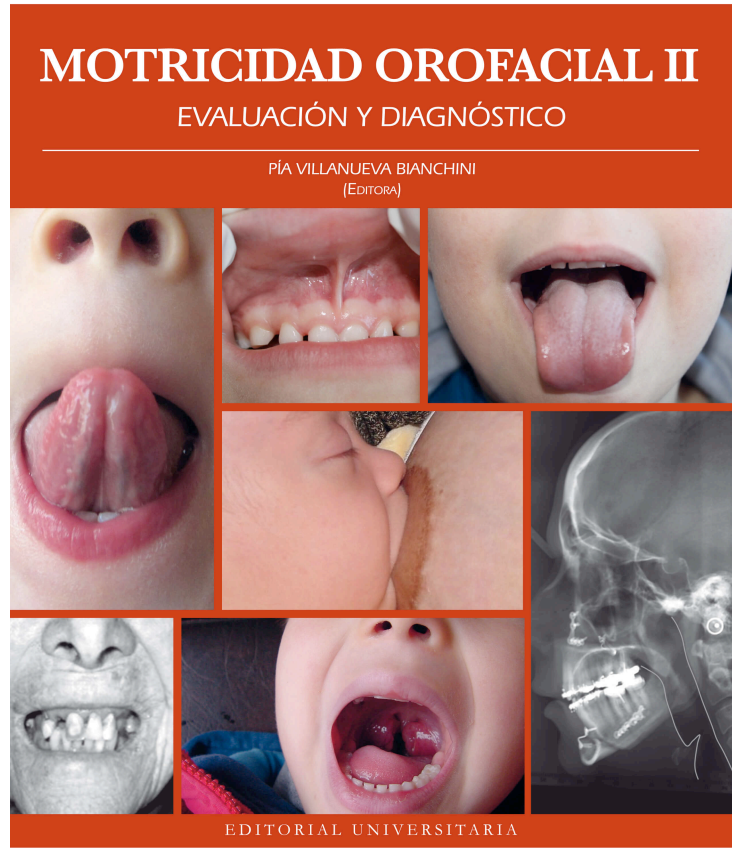

Editora: Pía Villanueva Bianchini

Editorial: Editorial Universitaria

Número de páginas: 158 páginas.

Año: 2017

ISBN: 978-956-11-2531-5

Datos de la editora: académica del Departamento de Fonoaudiología, Facultad de Medicina, Universidad de Chile. 
En Motricidad Orofacial II. Evaluación y diagnóstico, la editora Pía Villanueva continúa la valiosa labor emprendida anteriormente con la publicación del libro Motricidad Orofacial I. Fundamentos anatomofisiológicos y evolutivos para la Evaluación Clínica, el primer libro chileno en el área.

En Motricidad Orofacial II, la editora reúne en una extensa y meritoria labor a numerosos profesionales académicos de la Universidad de Chile, fonoaudiólogos y cirujanos dentistas, que contribuyen con su experiencia como autores de los capítulos de la obra.

El libro está compuesto por doce capítulos distribuidos en 158 páginas. El contenido aborda tópicos de interés para los clínicos que tratan las alteraciones oclusales e miofuncionales, tales como médicos, dentistas, además de fonoaudiólogos evidentemente. La mayoría de los capítulos contienen ilustraciones muy didácticas acerca de los problemas presentados y todos incorporan al final protocolos de evaluación que representan un aporte valioso para los clínicos vinculados con la temática.

El primer capítulo se refiere a la evaluación clínica de los órganos fonoarticulatorios. El protocolo que incluye está bien elaborado y es de fácil aplicación. Ello permite a los profesionales organizar su evaluación de forma práctica y objetiva. Lo anterior posibilita incluso construir una base de datos para lograr la comparación de información inter-pacientes o para comparar los datos del mismo paciente antes y después de la terapia, facilitando que padres y pacientes puedan entender las modificaciones que ocurren durante el proceso terapéutico.

A partir de ese capítulo, el cual es fundamental para una evaluación de las funciones orofaciales, los demás capítulos versan sobre las evaluaciones más específicas de las alteraciones de las funciones orofaciales a lo largo del ciclo vital y en diferentes patologías.

Se abordan así procedimientos para evaluar las alteraciones de la articulación temporomandibular, las funciones orofaciales en neonatos, las insuficiencias velofaríngeas, la salud oral en niños, los aspectos odontológicos en adultos mayores, la vía aérea superior, los trastornos de la deglución de niños portadores de parálisis cerebral, las funciones orofaciales en personas con cáncer de cabeza y de cuello, con disartrias o con trastornos motores. 
Es destacable en un libro de estas características, la adecuada percepción de la editora para abordar la evaluación y el diagnóstico de las alteraciones de la motricidad orofacial considerando las especificidades de las distintas patologías.

Al respecto, se puede señalar que las estructuras evaluadas en la motricidad orofacial son las mismas, o sea, boca, labios, dientes, mejillas, etc., sin embargo, el profesional que evalúa necesita conocer en detalle la alteración de base de cada patología que está atendiendo. Ello es necesario porque el protocolo puede ser incluso el mismo, pero como cada patología causa un trastorno o dificultad diferente, si quien evalúa no conoce en detalle la patología de base, así como los trastornos que origina, puede llegar a una conclusión errónea en su diagnóstico y posterior tratamiento.

El libro está muy bien escrito y su contenido es muy completo. Por ello, su lectura es recomendable para todos aquellos que quieran profundizar en la evaluación y el diagnóstico de las alteraciones de las funciones orofaciales. En particular, sería muy conveniente su uso en las universidades que tengan cursos de pregrado principalmente en el área de la fonoaudiología y de la odontología, así como para todos los profesionales que tratan las alteraciones de la motricidad orofacial. De esta manera, desde el pregrado se destacaría al futuro profesional la importancia de conocer no sólo "el todo" en términos de evaluación, sino cómo y principalmente qué patología causó la alteración en la función que deberá ser tratada.

De acuerdo a lo anterior, la editora y todos los demás profesionales que colaboran con sus conocimientos a la ejecución y desarrollo del contenido final del libro contribuyen con un gran aporte para la Motricidad Orofacial chilena, lo que merece una felicitación.

Por último, es recomendable que el libro, por sus características y aporte, esté presente en todas las clínicas donde los profesionales trabajan con pacientes portadores de alteraciones en las funciones orofaciales. 